\title{
Ascospore Inoculum Density and Characterization of Components of Partial Resistance to Sclerotinia sclerotiorum in Soybean
}

\author{
Jaqueline Huzar-Novakowiski and Anne E. Dorrance, ${ }^{\dagger}$ Department of Plant Pathology, The Ohio State University, Ohio Agricultural \\ Research and Development Center, Wooster 44691
}

\begin{abstract}
Germplasm screening programs have primarily relied on inoculation with mycelia to determine the resistance reaction of soybean genotypes to Sclerotinia sclerotiorum. However, under field conditions, ascospores are the primary source of inoculum. Therefore, the objective of this study was to determine which components most accurately differentiate the resistance reaction of soybean genotypes inoculated with ascospores of S. sclerotiorum. Ascospores were produced in the laboratory and all of the experiments were carried out under controlled conditions with inoculations at flowering stage. Initially, inoculum densities of $1 \times 10^{4}$, $1 \times 10^{5}$ and $1 \times 10^{6}$ ascospores $\mathrm{ml}^{-1}$ were compared on six soybean genotypes with known resistance reactions. Disease symptoms developed

on all genotypes and at all inoculum densities. The highest ascospore concentration increased infection efficiency but it was not correlated with an increase in lesion length. Components of resistance were then measured on a set of 17 cultivars with known resistance reactions at $1 \times 10^{5}$ ascospores $\mathrm{ml}^{-1}$. Resistance reactions could be differentiated based on the level of infection efficiency and lesion length on the main stem. Although inoculation with ascospores presents some limitations such as the time required for inoculum production as well as the time and space required for plant growth, it has the potential to be used to complement other methods for the characterization of resistance of soybean genotypes.
\end{abstract}

Host resistance is one of the most effective tactics to manage plant diseases that affect field crops. Disease resistance is generally classified as resistance $(R)$ gene (complete, monogenic, qualitative, racespecific, and vertical) or partial resistance (incomplete, polygenic, quantitative, nonrace specific, and horizontal) (Bent 1996; Bent and Mackey 2007; Gururani et al. 2012; Parlevliet 1979; St. Clair 2010). $R$ gene resistance is the result of the direct or indirect interaction between a product derived from a pathogen avirulence gene and a product of a plant $R$ gene (Bent and Mackey 2007; HammondKosack and Jones 1996). In contrast, partial resistance is controlled by multiple genes at multiple loci where genotypes can exhibit a continuum of resistance reactions (St. Clair 2010; Young 1996).

The reduced rate of disease development observed in plants with partial resistance toward plant pathogens is attributed to several components, including lower infection efficiency, longer latent period, longer incubation period, and reduced propagule production (Browne et al. 2005; Parlevliet 1979; Rashid 1991). Even with the advance of molecular techniques allowing the use of genetic markers for germplasm screening (Klos et al. 2000; Kumar et al. 2014; Shi et al. 2015; Vasudevan et al. 2014), selection for resistance in breeding programs of agricultural crops ultimately requires quantification of disease. Hence, assessment of components of resistance can provide insights about the infection and colonization process of the host by the pathogen, which could help in development of more reliable screening methods and, more importantly, greater understanding and better characterization of the genes contributing to resistance.

Partial resistance has been reported for Sclerotinia stem rot (SSR) of soybean (Hoffman et al. 2002; Kim and Diers 2000a; Kull et al. 2003) and several quantitative trait loci (QTL) have been mapped

${ }^{\dagger}$ Corresponding author: A. E. Dorrance; E-mail: dorrance.1@ osu.edu

Funding: This project was funded, in part, through check-off dollars provided by the Ohio Soybean Council, Hatch project for "Development of Disease Management Strategies for Soybean Pathogens in Ohio OHO01303". J. Huzar-Novakowiski is a graduate student funded by Coordenação de Aperfeiçoamento de Pessoal de Nível Superior (CAPES) through the Science without Borders Program from Brazil.

Accepted for publication 23 January 2018.

C) 2018 The American Phytopathological Society in the soybean genome (Arahana et al. 2001; Guo et al. 2008; Huynh et al. 2010; Vuong et al. 2008). Sclerotinia stem rot, also known as white mold, is caused by the fungus Sclerotinia sclerotiorum (Lib.) de Bary, and high levels of disease can occur under cool temperatures and moist conditions (Boland and Hall 1988). Management of SSR can be very challenging due to the wide host range of the pathogen (>400 host plants) (Boland and Hall 1994) and its capacity to survive in the soil as sclerotia for many years (Adams and Ayers 1979; Cook et al. 1975; Schwartz and Steadman 1978). Therefore, the use of host resistance is desirable especially for those fields with a long history of SSR incidence.

Previous studies to identify and characterize resistance have compared lesion development on stems (Auclair et al. 2004; Kull et al. 2003; Rousseau et al. 2004; Vuong et al. 2004), petioles (Peltier and Grau 2008; Willbur et al. 2017), and leaves (Kull et al. 2003) following inoculation with mycelial plugs of S. sclerotiorum. Although some studies also used ascospores for inoculation of soybean plants (Cline and Jacobsen 1983; Rousseau et al. 2004), more detailed characterization of components of partial resistance to $S$. sclerotiorum has not been completed in soybean. It is important to highlight that, in the selection process for high levels of partial resistance, evaluation of only one component may not represent the full potential for resistance or susceptibility of a particular genotype (Xue and Davidson 1998), especially because components may not be independent or may be affected by environmental conditions (Rashid 1991). For SSR, assessment of components of resistance include measurements of (i) disease incidence as the relative number of infected plants; (ii) the number of successfully infected flowers in a plant among the total inoculated; (iii) the extent of lesion expansion on the main stem, petiole, or branches; and iv) the number of sclerotia produced.

Because primary infection of $S$. sclerotiorum in soybean occurs through ascospores that land on blossoms located from 10 to $40 \mathrm{~cm}$ above the soil line (Boland and Hall 1988), inoculation with mycelia does not reproduce the natural infection process that is predominant in soybean fields. Therefore, we hypothesize that characterization of components of partial resistance to S. sclerotiorum with an ascospore inoculation method would not only provide a better understanding of infection and colonization of soybean but may also provide a reliable screening procedure to accurately differentiate levels of resistance in soybean. Thus, the objectives of the study were to (i) determine the effect of ascospore density on the expression of infection efficiency (IE) toward S. sclerotiorum; (ii) determine whether IE, disease severity index (DSI), and lesion length (LL) 
are different among genotypes with different levels of resistance; iii) identify and determine the relationship of the components; and iv) determine which components most accurately differentiate the reaction of soybean genotypes with known distinct levels of resistance to S. sclerotiorum under controlled conditions.

\section{Materials and Methods}

Sclerotia production. The S. sclerotiorum isolate OHSS13001, that represents the population from Ohio, was obtained from a naturally infected soybean plant collected from a field in 2013, and it was used for all assays. Diseased stem tissue was surface sterilized with $0.525 \%$ sodium hypochlorite solution for $1 \mathrm{~min}$, rinsed twice in sterile deionized water for $1 \mathrm{~min}$, and placed on potato dextrose agar (PDA) media. Hyphal tips were transferred twice to PDA media to obtain a pure culture. The sclerotia that formed on PDA after 14 days were transferred to $2-\mathrm{ml}$ microcentrifuge tubes and maintained at $4{ }^{\circ} \mathrm{C}$ until use. The method for sclerotia production was adapted from Yanar and Miller (2003). Potato tubers were cut transversally in pieces of approximately 3 to $5 \mathrm{~mm}$ in thickness and placed as a continuous layer in 298-by-235-mm aluminum trays. The trays were covered with aluminum foil and autoclaved at $121^{\circ} \mathrm{C}$ for $30 \mathrm{~min}$ on two consecutive days. To start a new culture, sclerotia were surface sterilized with $0.525 \%$ sodium hypochlorite solution for $1 \mathrm{~min}$, rinsed twice in sterile deionized water for $1 \mathrm{~min}$, and dried in a laminar flow hood for $30 \mathrm{~min}$. Sclerotia were placed in 100by-15-mm Petri dishes containing PDA and maintained at room temperature (approximately 23 to $25^{\circ} \mathrm{C}$ ) for 3 to 4 days until mycelial growth was observed. Hyphal tips were transferred to PDA and, after 2 days at room temperature, mycelial plugs cut from the margin of the growing culture were transferred to the autoclaved potato pieces. The trays were covered with aluminum foil and placed at room temperature for 3 weeks. Sclerotia were then harvested from the colonized potato pieces by washing with tap water to remove mycelia and potato pieces. Sclerotia were air dried in laminar flow hood for $48 \mathrm{~h}$ at room temperature, then stored at $4^{\circ} \mathrm{C}$ until use.

Ascospore production. Sclerotia were placed in cheesecloth bags and were conditioned following an adaptation of the method described by Pethybridge et al. (2015). Cheesecloth bags containing sclerotia were placed in a container with nonsterile distilled water in a cold room at $4^{\circ} \mathrm{C}$ for 6 weeks. During this time, air was continuously bubbled through the distilled water using an aquarium pump. Water was discarded each week and fresh distilled water was added to the container. Approximately 30 to 50 sclerotia were transferred to 100-by-15-mm glass Petri dishes containing sterile sand previously autoclaved at $121^{\circ} \mathrm{C}$ for $30 \mathrm{~min}$ on two consecutive days. The sand was kept at saturated levels with sterile deionized water, and the plates were maintained in a $15^{\circ} \mathrm{C}$ incubator under fluorescent light in a cycle of $12 \mathrm{~h}$ of light and $12 \mathrm{~h}$ of darkness. Stipes began to form approximately 3 to 4 weeks later. When stipes were fully expanded and mature apothecia were formed, ascospores were then collected onto sterile filter paper using a vacuum system immediately after opening the Petri dish lid (Steadman and Cook 1974). Paper filters were stored in glass jars containing calcium chloride as desiccant and were maintained at $4{ }^{\circ} \mathrm{C}$ until use within 6 months.

Ascospore inoculation. The paper filters were washed with sterile deionized water to prepare an ascospore suspension. Ascospores were counted with a hemocytometer and the density was adjusted according to parameters of each experiment. Tween 20 (Amresco, Solon, $\mathrm{OH}$ ) was added at $0.05 \%$ (vol/vol) to the suspension. For each study, plants were inoculated at full flowering stage, which is defined as the presence of an open flower at one of the two uppermost nodes on the main stem. Control plants were inoculated with sterile distilled water. Three to five nodes were inoculated per plant, starting from the fourth node up. After inoculation, plants were left to dry at room temperature for $1 \mathrm{~h}$ to prevent the inoculum from falling off the flower. The plants were then transferred to a mist bench with $90 \mathrm{~s}$ of mist every $5 \mathrm{~min}$, and maintained under mist until evaluation 7 to 10 days later. For every experiment, $100 \mu l$ of ascospore suspension was placed in three Petri dish plates containing water agar media, and germination of 100 ascospores in each plate was evaluated after $24 \mathrm{~h}$ to ensure that ascospores were viable and germination rate was greater than $85 \%$. Ascospores were considered germinated if the length of the germination tube was twice the diameter of the spore.

Soybean genotypes. The genotypes chosen to represent the different levels of resistance based on previous reports are listed in Table 1. Seed was obtained from the U.S. National Plant Germplasm System (https://www.ars-grin.gov/npgs/index.html). Six seeds of each genotype were sown in a $15-\mathrm{cm}$-diameter plastic pot containing sterile soil. The seed typically germinated within 7 days and, at the V1 growth stage (first expanded trifoliate leaf), they were thinned to four plants per pot. They remained in the greenhouse at $25 \pm 2{ }^{\circ} \mathrm{C}$ and a 14-h photoperiod until full flowering stage (open flower at one of the two uppermost nodes on the main

Table 1. List of soybean cultivars and their respective accession number, stem termination (ST), flower color (FC), hilum color (HC), maturity group (MG), and level of resistance (LR) to Sclerotinia sclerotiorum previously described in other studies

\begin{tabular}{|c|c|c|c|c|c|c|c|c|}
\hline Cultivar & Accession $^{\mathbf{a}}$ & $\mathbf{S T}^{\mathbf{b}}$ & $\mathbf{F C}^{\mathbf{c}}$ & $H^{d}$ & MG & $\mathbf{L R}^{\mathbf{e}}$ & Conditions & Reference \\
\hline A2506 & PI 561717 & I & $P$ & $\mathrm{BL}$ & 2 & $\mathrm{R}$ & Field, greenhouse, laboratory & Kim et al. 2000b \\
\hline Bell & PI 540554 & I & $\mathrm{P}$ & BL & 1 & I & Field, greenhouse & Wegulo et al. 1998 \\
\hline Chapman & PI 542710 & I & $\mathrm{P}$ & IB & 2 & I & Field, greenhouse, laboratory & Kim et al. $2000 \mathrm{~b}$ \\
\hline Colfax & PI 573008 & $\mathrm{D}$ & $\mathrm{W}$ & $\mathrm{BF}$ & 2 & $\mathrm{R}$ & Field, greenhouse, laboratory & Kim et al. 2000b \\
\hline Corsoy 79 & PI 518669 & I & $\mathrm{P}$ & $\mathrm{Y}$ & 2 & $\mathrm{R}$ & Field, greenhouse, laboratory & Kim et al. 2000b \\
\hline Dassel & PI 508083 & I & $\mathrm{P}$ & $\mathrm{Y}$ & 0 & $\mathrm{R}$ & Field, greenhouse & Wegulo et al. 1998 \\
\hline Dunbar & PI 552538 & I & $\mathrm{P}$ & IB & 3 & S & Field, greenhouse, laboratory & Kim et al. $2000 \mathrm{~b}$ \\
\hline Elgin & PI 548557 & I & $\mathrm{P}$ & $\mathrm{BL}$ & 2 & S & $\ldots$ & $\ldots$ \\
\hline Felix & PI 572245 & I & $\mathrm{W}$ & $\mathrm{Y}$ & 1 & I & Field, greenhouse, laboratory & Kim et al. 2000b \\
\hline Hardin & PI 548526 & I & $\mathrm{P}$ & $\mathrm{Y}$ & 1 & I & Field, greenhouse & Vuong et al. 2004 \\
\hline Jack & PI 540556 & I & $\mathrm{W}$ & $\mathrm{Y}$ & 3 & S & $\ldots$ & $\ldots$ \\
\hline Kottman & PI 612594 & I & W & $\mathrm{BL}$ & 3 & I & $\ldots$ & $\ldots$ \\
\hline NKS19-90 & PI 556897 & I & $\mathrm{P}$ & G & 1 & $\mathrm{R}$ & Field, greenhouse, laboratory & Kim et al. 2000b \\
\hline Olympus & PI 602060 & I & $P$ & BL & 2 & I & Field, greenhouse, laboratory & Kim et al. 2000b \\
\hline Parker & PI 562374 & I & W & $\mathrm{BF}$ & 1 & I & Field, greenhouse & Wegulo et al. 1998 \\
\hline Resnik & PI 534645 & I & $P$ & BL & 3 & S & Field, greenhouse, laboratory & Kim et al. $2000 \mathrm{~b}$ \\
\hline Williams 82 & PI 518671 & I & $\mathrm{W}$ & $\mathrm{BL}$ & 3 & S & Field, greenhouse & Wegulo et al. 1998 \\
\hline
\end{tabular}

a Accession number from the U.S. National Plant Germplasm System (https://www.ars-grin.gov/npgs/index.html).

${ }^{\mathrm{b}} \mathrm{ST}$ type: $\mathrm{I}=$ indeterminate and $\mathrm{D}=$ determinate.

${ }^{\mathrm{c}} \mathrm{P}=$ purple and $\mathrm{W}=$ white.

${ }^{\mathrm{d}} \mathrm{BL}=$ black, $\mathrm{BU}=$ buff, $\mathrm{G}=$ gray, $\mathrm{IB}=$ imperfect black, and $\mathrm{Y}=$ yellow.

${ }^{\mathrm{e}}$ Resistance reaction according to previous studies of germplasm screening for resistance to $S$. sclerotiorum: $\mathrm{S}=$ susceptible, $\mathrm{I}=$ intermediate resistant or susceptible, and $\mathrm{R}=$ resistant. 
stem). Plants were watered at least twice a day, and fertilization and insecticide sprays were applied as needed. Because the genotypes were from different maturity groups, they were planted on different dates, with an interval of 10 days between maturity groups, so that plants of all genotypes were at the same growth stage on the day of inoculation.

Evaluation of components of partial resistance. IE of flowers (IEF) was obtained by counting the number of flowers where presence of mycelial growth was observed. The number of infected flowers was then divided by the total number of inoculated flowers and multiplied by 100 for a percentage.

IE of plants (IEP) was determined based on the percentage of plants that exhibited a lesion on either the main stem or petiole following flower inoculation with ascospores, and the number was divided by the total number of plants inoculated.

DSI was evaluated based on the method adapted from Rousseau et al. (2004) using a scale from 0 to 5 , where $0=$ no symptoms, $1=$ inflorescence axis infected, $2=$ inflorescence axis totally infected, $3=$ stem infected, $4=$ lesion progressing in stem or petiole, and $5=$ wilted plant. DSI was calculated as follows: $\Sigma$ (severity class $\times$ number of plants per class) $\times 100 /$ (total number of plants $\times$ number of classes with symptoms) (Grau and Radke 1984).
LL was measured with a ruler from the inoculation site on the main stem (LLMS) and petiole (LLPET) to the lesion margin. LLMS and LLPET were considered individually or summed for the final measurement.

Effect of ascospore inoculum density. The experiment was carried out in a completely randomized design with six cultivars (Corsoy 79, Jack, Kottman, NKS19-90, Resnik, and Williams 82) and three ascospore inoculum densities $\left(1 \times 10^{4}, 1 \times 10^{5}\right.$, and $1 \times 10^{6}$ ascospores $\left.\mathrm{ml}^{-1}\right)$. These densities were determined to represent a range of amount of ascospores based on previous studies (Abawi et al. 1975; Rousseau et al. 2004). Three to five inflorescences in a plant were marked with tape to keep a record of the total number of flowers inoculated. A $20-\mu 1$ volume of inoculum was used to inoculate each inflorescence. There were three replicate pots with three plants per pot. The average of each pot was considered for statistical analysis. The whole experiment was repeated five times. The components of partial resistance evaluated were IE, DSI, and LL. The density that provided the most consistent and accurate differentiation of levels of resistance among genotypes was used for further experiments.

Validation of ascospore inoculation method. Seventeen soybean cultivars (Table 1), selected based on their known resistant reaction to $S$. sclerotiorum, were used in this experiment. Seed were obtained

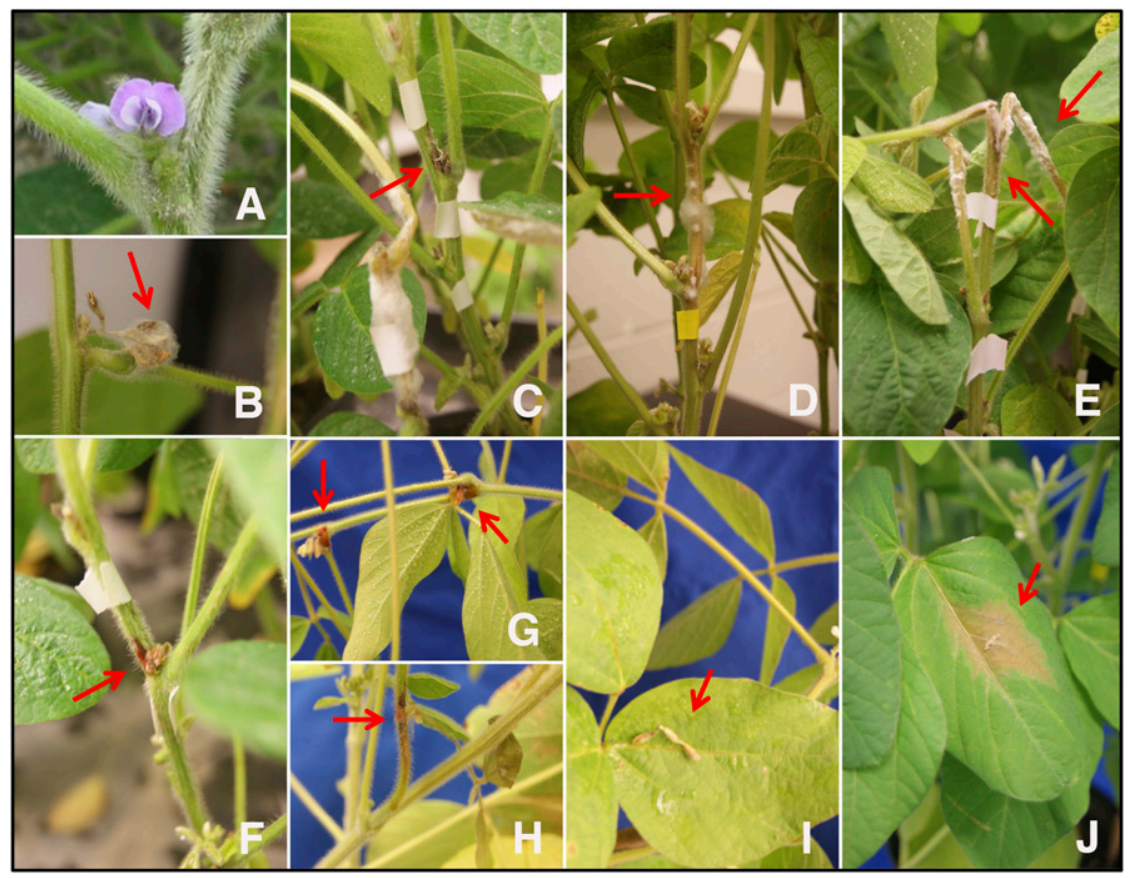

Fig. 1. Soybean plants inoculated with ascospores of Sclerotinia sclerotiorum. A, Open flower prior to inoculation; B, mycelial growth on inflorescence; C, lesion on the main stem; $\mathrm{D}$, lesion on petiole; and $\mathrm{E}$, lesion on both; $\mathrm{F}$ to $\mathrm{H}$, resistance reaction; I, infected flowers that fall off the node and land on leaves can $\mathrm{J}$, cause infection and lesion development. Pictures were taken 7 days after inoculation.

Table 2. Probability values $(P)$ for the effects of soybean cultivar, ascospore inoculum density, and interaction on disease severity index (DSI), infection efficiency of flowers (IEF), infection efficiency of plant (IEP), lesion length on main stem (LLMS), lesion length on petiole (LLPET), and sum of lesion length on both main stem and petiole (LLMS+PET)

\begin{tabular}{lrlrrrrr}
\hline Effect & Df & DSI $^{\mathbf{a}}$ & IEF $^{\mathbf{b}}$ & IEPc $^{\mathbf{c}}$ & LLMS $^{\mathbf{d}}$ & LLPET $^{\mathbf{d}}$ & LLMS+PET $^{-}$ \\
\hline Cultivar (C) & 5 & 0.001 & 0.007 & 0.154 & $<0.001$ & 0.025 & 0.028 \\
Inoculum density (ID) & 2 & 0.002 & $<0.001$ & 0.602 & 0.458 & 0.701 & 0.117 \\
C $\times$ ID & 10 & 0.967 & 0.793 & 0.519 & 0.410 & 0.081 & 0.127 \\
\hline
\end{tabular}

${ }^{a}$ DSI was evaluated using a scale from 0 to 5 (Rousseau et al. 2004), where $0=$ no symptoms, $1=$ inflorescence axis infected, $2=$ inflorescence axis totally infected, $3=$ stem infected, $4=$ lesion progressing on the stem or petiole, and $5=$ wilted plant. DSI was calculated as follows: $\Sigma$ (severity class $\times$ number of plants per class) $\times 100 /$ (total number of plants $\times$ number of classes with symptoms) (Grau and Radke 1984).

${ }^{\mathrm{b}} \mathrm{IEF}=$ number of infected flowers divided by the total number of inoculated flowers (three to five per plant) and multiplied by 100 for a percentage. Data were arcsine square root transformed for statistical analysis.

${ }^{\mathrm{c}} \mathrm{IEP}=$ number of plants that exhibited a lesion on either the main stem or petiole divided by the total number of plants inoculated and multiplied by 100 for a percentage. Data were arcsine square root transformed for statistical analysis.

${ }^{\mathrm{d}}$ Lesion length was measured from the inoculation site on the main stem (LLMS) and petiole (LLPET) to the lesion margin, and considered individually or summed as final measurement. 
from the U.S. National Plant Germplasm System (https://www.arsgrin.gov/npgs/index.html). Due to limited mist bench space and genotypes with different maturity groups, the experiment was carried out in an incomplete randomized block design with three replications, where each replication was one pot with three plants. The whole experiment was repeated five times. In all blocks, the cultivars
NKS19-90 and Williams 82 were included as resistant and susceptible checks, respectively. The components of partial resistance evaluated were IE, DSI, and LL.

Data analysis. Homogeneity of variance was analyzed using residual plots for each one of the components. Variance was homogenized using an arcsine square root transformation for IE, whereas

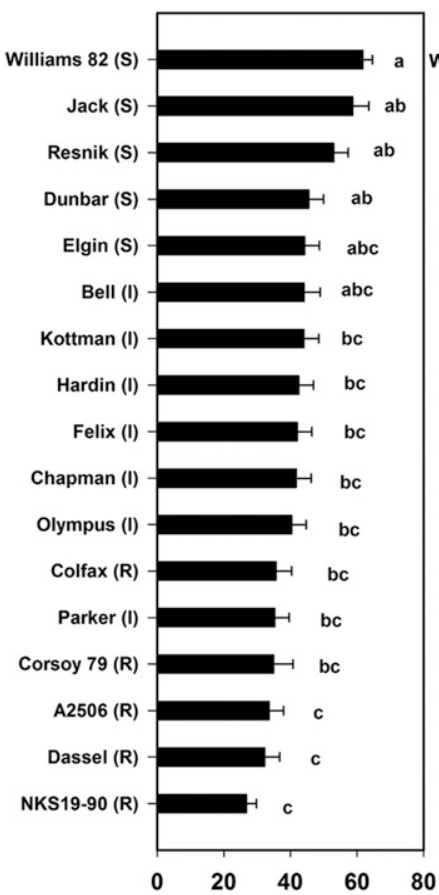

DSI

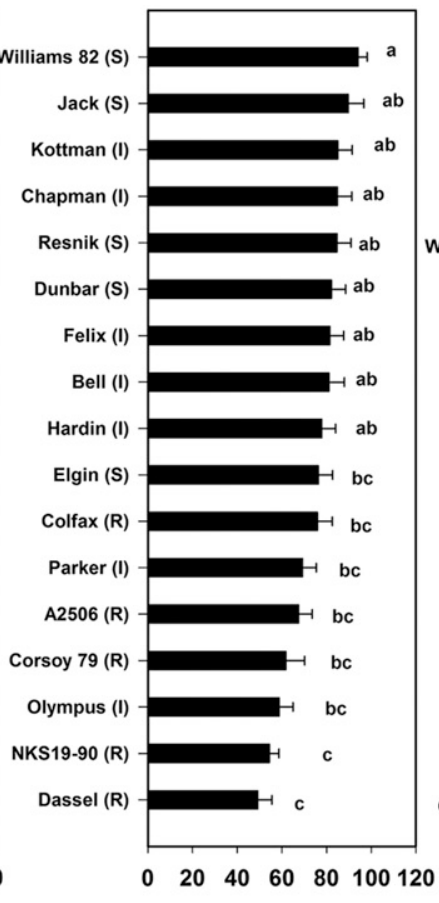

IEF (\%)
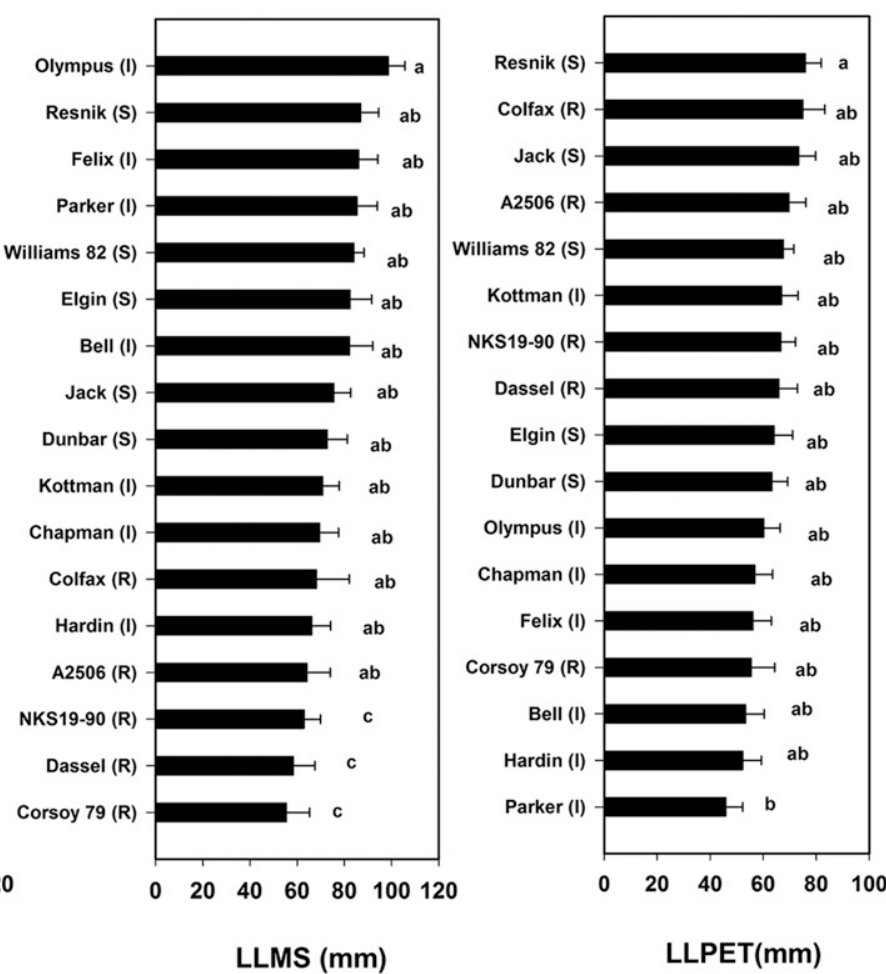

Fig. 2. Mean of disease severity index (DSI), infection efficiency of flowers (IEF, back transformed, percent), and lesion length on main stem (LLMS, millimeters) of six soybean genotypes inoculated with three densities of ascospores of Sclerotinia sclerotiorum. Bars represent the standard error of the mean. Capital letters represent the mean comparison of cultivar and lowercase letters represent the mean comparison of ascospore inoculum density.

Table 3. Rank of soybean cultivars based on disease severity index (DSI), infection efficiency of flower (IEF), infection efficiency of plant (IEP), lesion length on main stem (LLMS), lesion length on petiole (LLPET), and sum of lesion length on both main stem and petiole (LLMS+PET) at three different ascospore inoculum density (Density) of Sclerotinia sclerotiorum

\begin{tabular}{|c|c|c|c|c|c|c|}
\hline \multirow[b]{2}{*}{ Density (ascospore $\mathrm{ml}^{-1}$ ) } & \multicolumn{6}{|c|}{ Soybean cultivar ranks } \\
\hline & Corsoy 79 & NKS19-90 & Kottman & Jack & Resnik & Williams 82 \\
\hline \multicolumn{7}{|l|}{$\overline{\mathrm{DSI}}$} \\
\hline $1 \times 10^{4}$ & 1 & 2 & 3 & 5 & 4 & 6 \\
\hline $1 \times 10^{5}$ & 1 & 2 & 3 & 4 & 5 & 6 \\
\hline $1 \times 10^{6}$ & 2 & 1 & 3 & 5 & 4 & 6 \\
\hline \multicolumn{7}{|l|}{ IEF } \\
\hline $1 \times 10^{4}$ & 2 & 1 & 3 & 5 & 4 & 6 \\
\hline $1 \times 10^{5}$ & 1 & 2 & 3 & 4 & 5 & 6 \\
\hline $1 \times 10^{6}$ & 1 & 2 & 3 & 5 & 4 & 6 \\
\hline \multicolumn{7}{|l|}{ IEP } \\
\hline $1 \times 10^{4}$ & 2 & 1 & 4 & 6 & 5 & 3 \\
\hline $1 \times 10^{5}$ & 4 & 1 & 3 & 2 & 6 & 5 \\
\hline $1 \times 10^{6}$ & 3 & 1 & 4 & 5 & 2 & 6 \\
\hline \multicolumn{7}{|l|}{ LLMS } \\
\hline $1 \times 10^{4}$ & 4 & 3 & 1 & 2 & 5 & 6 \\
\hline $1 \times 10^{5}$ & 3 & 1 & 4 & 2 & 5 & 6 \\
\hline $1 \times 10^{6}$ & 4 & 1 & 2 & 3 & 5 & 6 \\
\hline \multicolumn{7}{|l|}{ LLPET } \\
\hline $1 \times 10^{4}$ & 2 & 5 & 6 & 1 & 4 & 3 \\
\hline $1 \times 10^{5}$ & 1 & 2 & 6 & 4 & 3 & 5 \\
\hline $1 \times 10^{6}$ & 2 & 3 & 4 & 1 & 5 & 6 \\
\hline \multicolumn{7}{|l|}{ LLMS+PET } \\
\hline $1 \times 10^{4}$ & 1 & 4 & 5 & 3 & 6 & 2 \\
\hline $1 \times 10^{5}$ & 2 & 1 & 5 & 3 & 4 & 6 \\
\hline $1 \times 10^{6}$ & 1 & 4 & 2 & 3 & 5 & 6 \\
\hline
\end{tabular}


DSI and LL were not transformed. Replicates nested within experiment and experiments were considered random effects, whereas cultivars and ascospore density were considered as fixed factors. The data were analyzed using PROC MIXED of SAS 9.4 (SAS Institute Inc., Cary, NC), and least-square means were calculated. For factors with significant differences $(P<0.05)$, a Tukey-Kramer multiple-range test was used for analysis, as described previously (Mideros et al. 2007). The rank of genotypes for each variable was obtained using PROC RANK, and the degree of relationship between components was determined based on Spearman's rank correlation coefficient calculated with PROC CORR.

\section{Results}

Disease development. Soybean plants placed in a mist bench after inoculation with ascospores of $S$. sclerotiorum developed symptoms and exhibited mycelial growth on the inflorescences (Fig. 1B). The earliest symptoms usually appeared within 4 to 5 days after inoculation. Rapidly expanding lesions were observed either on the petiole, up and down in the main stem, or both (Fig. 1C to E). Complete collapse of the stem was observed for the highly susceptible cultivars compared with those cultivars with greater levels of resistance, where lesion development was limited. Occasionally, red coloration was observed on the lesions of cultivars with higher levels of resistance (Fig. 1F to $\mathrm{H}$ ). Additionally, infected flowers that fell off the nodes and landed on leaves caused infection and lesion development (Fig. 1I and J). Development of sclerotia was observed occasionally from the white fluffy mycelia that grew on the colonized tissues.

Ascospore inoculum density. Soybean cultivar had significant effect on DSI, IEF, LLMS, LLPET, and LLMS+PET (Table 2), indicating that there was a wide range of resistance to susceptible responses. Ascospore inoculum density significantly affected DSI and IEF. However, no significant effect was observed for the interaction of soybean cultivar and inoculum density for any of the variables evaluated. DSI and IEF varied from 33 to 61 and 51 to $87 \%$, respectively, among the six soybean genotypes inoculated with different ascospore densities (Fig. 2). Inoculation with the lowest ascospore density $\left(1 \times 10^{4}\right.$ ascospores $\left.\mathrm{ml}^{-1}\right)$ had the lowest DSI and IEF, whereas the intermediate $\left(1 \times 10^{5}\right.$ ascospore $\left.\mathrm{ml}^{-1}\right)$ and highest $\left(1 \times 10^{6}\right.$

Table 4. Correlation coefficients of the ranks (below diagonal) and probability values (above diagonal) among the variables used to evaluate six soybean cultivars for resistance to Sclerotinia sclerotiorum

\begin{tabular}{|c|c|c|c|c|c|c|}
\hline Variable & DSI & IEF & IEP & LLMS & LLPET & LLMS + PET \\
\hline \multicolumn{7}{|c|}{$1 \times 10^{4}$ ascospores $\mathrm{ml}^{-1}$} \\
\hline DSI & $\ldots$ & 0.00 & 0.21 & 0.54 & 0.62 & 0.87 \\
\hline IEF & 0.94 & $\ldots$ & 0.16 & 0.47 & 0.40 & 0.87 \\
\hline IEP & 0.60 & 0.66 & $\ldots$ & 0.70 & 0.54 & 0.47 \\
\hline LLMS & 0.31 & 0.37 & -0.20 & $\ldots$ & 0.62 & 0.62 \\
\hline LLPET & -0.26 & -0.43 & -0.31 & -0.26 & $\ldots$ & 0.16 \\
\hline LLMS+PET & 0.09 & -0.09 & 0.37 & -0.26 & 0.66 & $\ldots$ \\
\hline \multicolumn{7}{|c|}{$1 \times 10^{5}$ ascospores $\mathrm{ml}^{-1}$} \\
\hline DSI & $\ldots$ & $<0.0001$ & 0.27 & 0.11 & 0.21 & 0.07 \\
\hline IEF & 1.00 & $\ldots$ & 0.27 & 0.11 & 0.21 & 0.07 \\
\hline IEP & 0.54 & 0.54 & $\ldots$ & 0.02 & 0.87 & 0.21 \\
\hline LLMS & 0.71 & 0.71 & 0.89 & $\ldots$ & 0.33 & 0.02 \\
\hline LLPET & 0.60 & 0.60 & 0.09 & 0.49 & $\ldots$ & 0.04 \\
\hline LLMS+PET & 0.77 & 0.77 & 0.60 & 0.89 & 0.83 & $\ldots$ \\
\hline \multicolumn{7}{|c|}{$1 \times 10^{6}$ ascospores $\mathrm{ml}^{-1}$} \\
\hline DSI & $\ldots$ & 0.00 & 0.04 & 0.11 & 0.47 & 0.27 \\
\hline IEF & 0.94 & $\ldots$ & 0.11 & 0.27 & 0.40 & 0.11 \\
\hline IEP & 0.83 & 0.71 & $\ldots$ & 0.33 & 0.79 & 0.79 \\
\hline LLMS & 0.71 & 0.54 & 0.49 & $\ldots$ & 0.27 & 0.33 \\
\hline LLPET & 0.37 & 0.43 & 0.14 & 0.54 & $\ldots$ & 0.11 \\
\hline LLMS+PET & 0.54 & 0.71 & 0.14 & 0.49 & 0.71 & $\ldots$ \\
\hline
\end{tabular}

${ }^{\mathrm{a}}$ DSI = disease severity index; IEF = infection efficiency of flower; IEP = infection efficiency of plants; LLMS = lesion length (millimeters) on main stem; LLPET = lesion length (millimeters) on petiole; LLMS+PET = sum of lesion length (millimeters) on main stem and petiole.
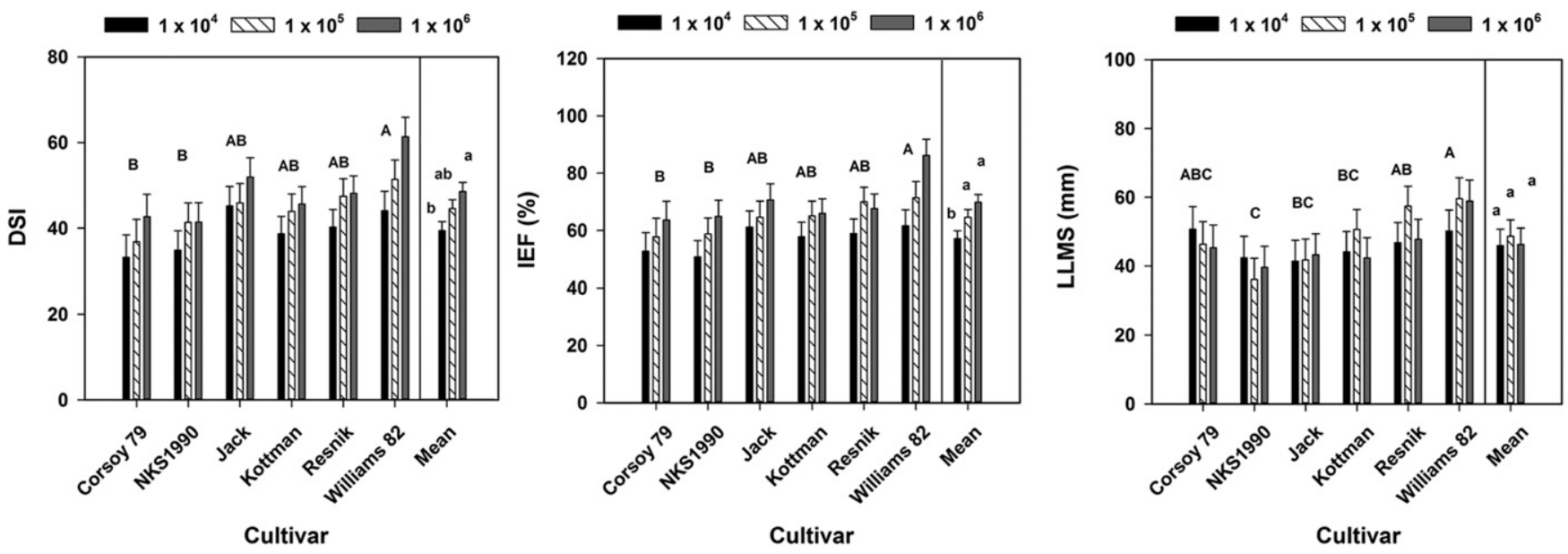

Fig. 3. Estimated least square means of disease severity index (DSI), infection frequency of flowers (IEF, percent), lesion length on main stem (LLMS, millimeters), and lesion length on petiole (LLPET, millimeters) of 17 soybean cultivars inoculated with ascospores of Sclerotinia sclerotiorum. Bars represent the standard error of the means. Means followed by different letters do not differ significantly from each other by Tukey-Kramer's test. 
ascospore $\mathrm{ml}^{-1}$ ) ascospore density did not differ from each other for DSI and IEF (Fig. 2). The cultivars NKS19-90 and Corsoy 79 had significantly lower DSI and IEF compared with Williams 82. NKS19-90 also had significantly lower LLMS compared with Williams 82 and Resnik (Fig. 2).

Corsoy and NKS19-90 had the lowest rank at each of the three ascospore inoculum densities, whereas Williams 82 had the highest rank for DSI and IEF (Table 3). These results agreed with their level of resistance reported in the literature as resistant and very susceptible (Table 1), respectively. The highest significant correlation was observed for DSI and IEF, which varied from 0.94 to 1.0 depending on the inoculum density (Table 4).

Due to the greater consistency of response and the lower number of ascospores required to make the suspensions, the intermediate ascospore density $\left(1 \times 10^{5}\right.$ ascospore $\left.\mathrm{ml}^{-1}\right)$ was chosen over the low and high densities as the standard for further experiments.

Validation of ascospore inoculation method. Seventeen soybean cultivars were used to validate the inoculation method with ascospores. The results indicated that DSI varied from 27 (NKS19-90) to 62 (Williams 82), IEF varied from $49 \%$ (Dassel) to $94 \%$ (Williams 82), and LLMS varied from $55 \mathrm{~mm}$ (Corsoy 79) to $99 \mathrm{~mm}$ (Olympus). Contrast analysis of the means according to the resistance level class indicated that resistant cultivars had lower DSI, IEF, and LLMS compared with intermediate and susceptible cultivars (Fig. 3). The intermediate class had lower DSI and IEF than the susceptible class but did not differ according to LLMS.

The rank of the soybean cultivars for each variable was between 1 and 17, indicating the most resistant to the most susceptible,

Table 5. Ranks ( 1 = most resistant $)$ of soybean cultivars for resistance to $S c l e$ rotinia sclerotiorum based on the results from this study following inoculation of flowers with ascospores, and from previous studies of resistance reaction in field trials

\begin{tabular}{|c|c|c|c|c|c|c|c|}
\hline \multirow[b]{2}{*}{ Cultivar } & \multicolumn{4}{|c|}{$\begin{array}{l}\text { Ascospore inoculation } \\
\text { in greenhouse }\end{array}$} & \multicolumn{3}{|c|}{$\begin{array}{l}\text { Evaluation of } \\
\text { in field trials }\end{array}$} \\
\hline & DSI & IEF (\%) & LLMS & $\overline{\text { LLPET }}$ & $\mathbf{D S I}^{\mathbf{b}}$ & DI $^{c}$ & DSI $^{d}$ \\
\hline A2506 & 4 & 5 & 7 & 15 & 2 & 2 & $\ldots$ \\
\hline Bell & 12 & 12 & 12 & 3 & $\ldots$ & 10 & $\ldots$ \\
\hline Corsoy 79 & 3 & 2 & 1 & 7 & 4 & $\ldots$ & 1 \\
\hline Chapman & 9 & 13 & 6 & 5 & 12 & 3 & $\ldots$ \\
\hline Colfax & 6 & 7 & 5 & 14 & 3 & $\ldots$ & $\ldots$ \\
\hline Dassel & 2 & 1 & 2 & 11 & $\ldots$ & 1 & $\ldots$ \\
\hline Dunbar & 14 & 11 & 9 & 9 & 15 & $\ldots$ & $\ldots$ \\
\hline Elgin & 11 & 8 & 11 & 8 & 11 & $\ldots$ & $\ldots$ \\
\hline Felix & 8 & 10 & 16 & 4 & 9 & $\ldots$ & $\ldots$ \\
\hline Hardin & 10 & 9 & 4 & 2 & 6 & $\ldots$ & 2 \\
\hline Jack & 16 & 16 & 10 & 16 & 10 & $\ldots$ & $\ldots$ \\
\hline Kottman & 13 & 14 & 8 & 12 & $\ldots$ & $\ldots$ & $\ldots$ \\
\hline NKS19-90 & 1 & 3 & 3 & 10 & 1 & 4 & 5 \\
\hline Olympus & 7 & 4 & 17 & 6 & 5 & $\cdots$ & $\ldots$ \\
\hline Parker & 5 & 6 & 13 & 1 & $\ldots$ & 5 & $\ldots$ \\
\hline Resnik & 15 & 15 & 15 & 17 & 17 & $\ldots$ & $\ldots$ \\
\hline Williams 82 & 17 & 17 & 14 & 13 & $\ldots$ & 11 & $\ldots$ \\
\hline $\begin{array}{l}\text { Total of } \\
\text { varieties tested }\end{array}$ & 17 & 17 & 17 & 17 & 18 & 12 & 15 \\
\hline
\end{tabular}

a Variables: DSI = disease severity index, IEF = infection efficiency $(\%)$,

LLMS = lesion length (millimeters) on main stem, and LLPET = lesion length (millimeters) on petiole.

${ }^{\mathrm{b}}$ DSI = disease severity index calculated by the following formula DSI = $[\Sigma$ (rating of each plant $) / 3 \times$ number of plants rated $] / 100$. Fields were inoculated with sclerotia or relied on natural inoculum for infection (Kim et al. 2000).

${ }^{\mathrm{c}}$ DI $=$ disease incidence. Fields were artificially infested with sclerotia (Wegulo et al. 1998).

d DSI $=$ disease severity was evaluated based on the scale $0=$ no symptoms, 1 $=$ lesions only found on lateral branches, $2=$ small lesions on main stem not affecting pod fill, and $3=$ lesions on main stem resulting in poor pod fill. DSI was calculated the formula DSI $=\{[$ sum of ratings for each plant $] /[3 \times$ number of plants rated] $\} \times 100$. Fields were inoculated with infested sorghum grain (Vuong et al. 2004). respectively (Table 5). To facilitate the interpretation, the correlation coefficient of the ranks between each pair of variables was calculated (Table 6). DSI and IEF had the highest significant correlation coefficient of 0.93 . DSI was also significantly correlated with LLMS. There was no correlation for LLPET with any variable.

\section{Discussion}

Accurate differentiation of levels of resistance to plant pathogens is essential, and a reliable screening procedure is necessary to ensure effective identification of genes and mechanisms of resistance. In an initial study with 6 soybean cultivars at three inoculum densities, and in a second evaluation of 17 cultivars, components of partial resistance to $S$. sclerotiorum were identified. The soybean cultivars evaluated represented a range of resistance reactions to the pathogen, and differences in the components were observed among the genotypes, which may indicate the presence of distinct mechanisms of resistance.

The cultivars and the ascospore inoculum densities significantly affected the response for DSI and IEF and may be the best means to measure these two components. The increase in ascospore inoculum density had higher IEF, LLMS, and DSI. Similar effects of inoculum density on plant diseases have been reported for several other pathosystems such as Fusarium wilt on summer squash (Caperton et al. 1986), Fusarium basal rot of onion (Gei et al. 2014), Fusiform rust on loblolly pine (Kuhlman et al. 1997), and potato late blight (Stewart 1990). The intermediate density of $1 \times 10^{5}$ ascospores $\mathrm{ml}^{-1}$ allowed for more consistent differentiation of resistance levels compared with the lowest density of $1 \times 10^{4}$ ascospores $\mathrm{ml}^{-1}$ and the highest density of $1 \times 10^{6}$ ascospores $\mathrm{ml}^{-1}$. A wide range of resistance reactions were identified for the 17 genotypes evaluated with inoculation of $1 \times 10^{5}$ ascospores $\mathrm{ml}^{-1}$. NKS19-90, Corsoy 79, and Dassel were identified as having the highest degree of partial resistance (similar ranks) among the cultivars tested, which was expressed by lower IEF, LLMS, and DSI. Williams 82 and Resnik exhibited the highest susceptibility, characterized by higher IEF, LLMS, and DSI. These results are all consistent with previous reports of screening for resistance to $S$. sclerotiorum (Kim et al. 1999; Rojas 2014; Wegulo et al. 1998). More importantly, the ranks for IEF and LLMS were very different for the cultivars Chapman, Elgin, Felix, Hardin, Jack, Kottman, Olympus, and Parker (Table 5).

The size of lesion on the stem has often been a criterion used to assess resistance levels of soybean genotypes to $S$. sclerotiorum (Auclair et al. 2004; Kull et al. 2003; Rousseau et al. 2004; Vuong et al. 2004). Even though IEF and LLMS were significantly correlated $(P=0.05)$ in this study, the correlation coefficient was moderate $(r=0.47)$. Each variable was able to separate resistant from susceptible cultivars but the rank of those cultivars with an intermediate response was not consistent between IEF and LLMS. These results suggested that a single component may not suffice to explain partial resistance of a particular genotype, and may indicate the presence of multiple mechanisms in cultivars with high levels of resistance to the pathogen that can only be measured with more than one type of assay. Additionally cultivars with the highest levels of resistance must have resistance to infection (IEF) as well as colonization (lesion size).

The ability of S. sclerotiorum to invade and the mode of penetration of host tissues depends upon the type of inoculum, properties of the host, environment, and nutrient status of the fungus (Lumsden

Table 6. Correlation coefficients (below diagonal) and probability values (above diagonal) among variables used to evaluate resistance of soybean genotypes to Sclerotinia sclerotiorum

\begin{tabular}{lcccc}
\hline Variable $^{\mathbf{a}}$ & DSI & IEF & LLMS & LLPET \\
\hline DSI & $\ldots$ & $<0.01$ & 0.03 & 0.33 \\
IEF & 0.93 & $\ldots$ & 0.05 & 0.33 \\
LLMS & 0.53 & 0.47 & $\ldots$ & 0.79 \\
LLPET & 0.25 & 0.25 & -0.07 & $\ldots$ \\
\hline
\end{tabular}

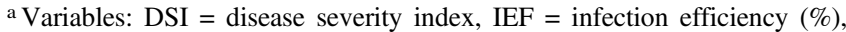
LLMS = lesion length (millimeters) on main stem, and LLPET = lesion length (millimeters) on petiole. 
1979). Both types of inoculum (ascospores and mycelia) can initiate infection of soybean (Cline and Jacobsen 1983). Ascospores require an external energy source such as petals to initiate infection (Sutton and Deverall 1983). In many inoculation methods with mycelia, a cut of the petiole or main stem is made and mycelial plugs are placed on the excision site (Kull et al. 2003; Peltier and Grau 2008; Vuong et al. 2004; Willbur et al. 2017). Even though infection is optimized, the barrier that includes the cuticle and epidermis is ignored and resistance is only characterized based on the lesion size. Several molecular mapping studies aiming to identify QTL responsible for the partial resistance in soybean genotypes have used these methods of inoculation on stems (Guo et al. 2008; Vuong et al. 2008) or leaves (Arahana et al. 2001). However, as discussed by Browne et al. (2005) in Fusarium head blight of wheat, the diversity and complexity of polygenic resistance makes the process for obtaining highly resistant and commercially acceptable cultivars very challenging if based solely on one screening method; therefore, the authors suggested that two methods should be used for molecular mapping of the partial resistance. Similarly, Colon et al. (1995) verified that the importance of individual components of resistance varied between Solanum spp., and that a great level of complexity and variability exists in the interaction with Phytophthora infestans. In the Septoria nodorum-wheat pathosystem, significant differences in lesion area were observed for cultivars of similar field resistance ratings (Lancashire and Jones 1985), and incubation period could not be used alone to accurately predict the resistance; sporulation was the component that could be used with more confidence (Griffiths and Jones 1987).

Several mechanisms may be associated with resistance to Sclerotinia sclerotiorum. The rate of diffusion of oxalic acid in the plant tissue has been associated with resistance levels (Tu 1985), and higher rates of wilting were observed in a susceptible soybean cultivar compared with a partially resistant cultivar (Rojas 2014). Oxalic acid can interfere in water conductance in the plant due to deregulation of guard cells of stomata by interacting with abscisic acid, breaking down starch, and accumulating potassium (Guimarães and Stotz 2004). In situ flower inoculation showed that the soybean plants that overexpressed an introduced oxalate oxidase gene were highly resistant to $S$. sclerotiorum compared with susceptible wild types (Davidson et al. 2016). In addition to the rate of diffusion of oxalic acid, cytoplasm disorganization and reinforced cell walls in epidermal and cortical cells (Rojas 2014), accumulation of phenolic compounds on cell walls of epidermal and cortical cell layers (Rojas 2014), and formation of phytoalexins (Favaron et al. 1988; Sutton and Deverall 1984) are some examples that have been found in association with resistance reaction in soybean.

Inoculum production per se or latent period (period from infection to sporulation) are also components of resistance measured in several other pathosystems such Melampsora lini in flax (Rashid 1991), Fusarium head blight in wheat (Browne et al. 2005), P. infestans in Solanum spp. (Colon et al. 1995), and Magnaporthe grisea in tall fescue (Tredway et al. 2003), among many others. Rojas (2014) observed that a higher number of sclerotia were produced on leaves of a susceptible soybean cultivar colonized with S. sclerotiorum compared with a partially resistant cultivar. However, because several nutritional and environmental factors can also affect the formation of sclerotia, the numbers were not consistent between the experiments and this measurement was not considered in our evaluations.

Ascospore inoculation does require more time for inoculum production compared with the inoculation of individual plants with mycelia. Additionally, the period of time required to grow the plants until flowering stage may be influenced by the time of year (winter or summer), use of supplemental lights in the greenhouse, and maturity groups of the genotypes. The challenge of screening soybean plants from different maturity groups was surpassed by planting multiple sets of checks on different dates, 7 to 10 days apart for each maturity group.

Partial resistance to SSR can be affected by environment (Peltier and Grau 2008; Pennypacker and Risius 1999; Waliyar et al.
1994), and escape mechanisms such as upright and less dense canopy, resistance to lodging, flowering date, and maturity date have been associated with lower levels of SSR of soybean in the field (Kim et al. 1999; McDonald et al. 2013). Thus, screening under controlled conditions does not eliminate the need for screening under field conditions but can help in selecting genotypes to be tested in the field, thus reducing labor and costs, as well as be an option for those years when the environment is not conducive for disease to develop in the field. Further studies are needed on the influence of ascospore inoculum from multiple isolates of $S$. sclerotiorum that represent the genetic diversity of the location where the cultivars are aimed to be used, as suggested by Willbur et al. (2017), as well as methodology to move this to a more high-throughput method for large-scale phenotyping.

Identification of resistance to $S$. sclerotiorum is required for selection of soybean genotypes that could be used in a breeding program for development of cultivars with higher levels of resistance intended to minimize yield losses. The results from this study demonstrated that ascospore inoculum density affected the level of IE, LLMS, and DSI. Screening programs should include ascospore inoculation as a complementary method, and not rely solely on mycelial inoculation, which could help in screening for resistance and, consequently, the deployment of resistance more effectively. Because QTL for partial resistance already identified in soybean are associated with LLMS, further studies are needed to verify whether a different QTL would be found related to infection frequency. In the future, pyramiding of QTL that are associated with different components of resistance potentially may elevate the degree of partial resistance to Sclerotinia stem rot of soybean in commercial cultivars.

\section{Acknowledgments}

We thank B. James for all of his help with the plants in the greenhouse, L. Wilson and K. Hartzler for finding greenhouse space for our experiments, and all of the students and interns of the Soybean Pathology Laboratory for help with watering the plants and evaluations.

\section{Literature Cited}

Abawi, G. S., Polach, F. J., and Molin, W. T. 1975. Infection of bean by ascospores of Whetzelinia sclerotiorum. Phytopathology 65:673-678.

Adams, P. B., and Ayers, W. A. 1979. Ecology of Sclerotinia species. Phytopathology 69:896-899.

Arahana, V. S., Graef, G. L., Specht, J. E., Steadman, J. R., and Eskridge, K. M. 2001. Identification of QTLs for resistance to Sclerotinia sclerotiorum in soybean. Crop Sci. 41:180-188.

Auclair, J., Boland, G. J., Cober, E., Graef, G. L., Steadman, J. R., Zilka, J., and Rajcan, I. 2004. Development of a new field inoculation technique to assess partial resistance in soybean to Sclerotinia sclerotiorum. Can. J. Plant Sci $84: 57-64$

Bent, A. F. 1996. Plant disease resistance genes: Function meets structure. Plant Cell 8:1757-1771.

Bent, A. F., and Mackey, D. 2007. Elicitors, effectors, and $R$ genes: The new paradigm and a lifetime supply of questions. Annu. Rev. Phytopathol. 45:399-436.

Boland, G. J., and Hall, R. 1988. Epidemiology of Sclerotinia stem rot of soybean in Ontario. Phytopathology 78:1241-1245.

Boland, G. J., and Hall, R. 1994. Index of plant hosts of Sclerotinia sclerotiorum Can. J. Plant Pathol. 16:93-108.

Browne, R. A., Murphy, J. P., Cooke, B. M., Devaney, D., Walsh, E. J., Griffey, C. A., Hancock, J. A., Harrison, S. A., Hart, P., Kolb, F. L., McKendry, A. L., Milus, E. A., Sneller, C., and Van Sanford, D. A. 2005. Evaluation of components of Fusarium head blight resistance in soft red winter wheat germ plasm using a detached leaf assay. Plant Dis. 89:404-411.

Caperton, C. M., Martyn, R. D., and Starr, J. L. 1986. Effect of inoculum density and root-knot nematodes on wilt resistance in summer squash. Plant Dis. 70: 207-209.

Cline, M. N., and Jacobsen, B. J. 1983. Methods for evaluating soybean cultivars for resistance to Sclerotinia sclerotiorum. Plant Dis. 67:784-786.

Colon, L. T., Budding, D. J., Keizer, L. C. P., and Pieters, M. M. J. 1995 Components of resistance to late blight (Phytophthora infestans) in eight South American Solanum species. Eur. J. Plant Pathol. 101:441-456.

Cook, G. E., Steadman, J. R., and Boosalis, M. G. 1975. Survival of Whetzelinia sclerotiorum and initial infection of dry edible beans in western Nebraska. Phytopathology 65:250-255.

Davidson, A. L., Blahut-Beatty, L., Itaya, A., Zhang, Y., Zheng, S., and Simmonds, D. 2016. Histopathology of Sclerotinia sclerotiorum infection and oxalic acid function in susceptible and resistant soybean. Plant Pathol. 65:878-887. 
Favaron, F., Alghisi, P., Marciano, P., and Magro, P. 1988. Polygalacturonase isoenzymes and oxalic acid produced by Sclerotinia sclerotiorum in soybean hypocotyls as elicitors of glyceollin. Physiol. Mol. Plant Pathol. 33:385-395.

Gei, P. F. C., Valdez, J. A., Piccolo, R. J., and Galmarini, C. R. 2014. Influence of Fusarium spp. isolate and inoculum density on resistance screening tests in onion. Trop. Plant Pathol. 39:19-27.

Grau, C. R., and Radke, V. L. 1984. Effects of cultivars and cultural practices on Sclerotinia stem rot of soybean. Plant Dis. 68:56-58.

Griffiths, B. Y. H. M., and Jones, D. G. 1987. Components of partial resistance as criteria for identifying resistance. Ann. Appl. Biol. 110:603-610.

Guimarães, R. L., and Stotz, H. U. 2004. Oxalate production by Sclerotinia sclerotiorum deregulates guard cells during infection. Plant Physiol. 136:3703-3711.

Guo, X., Wang, D., Gordon, S. G., Helliwell, E., Smith, T., Berry, S. A., St. Martin, S. K., and Dorrance, A. E. 2008. Genetic mapping of QTLs underlying partial resistance to Sclerotinia sclerotiorum in soybean PI 391589A and PI 391589B. Crop Sci. 48:1129-1139.

Gururani, M. A., Venkatesh, J., Prakash Upadhyaya, C., Nookaraju, A., Pandey, S. K., and Park, S. W. 2012. Plant disease resistance genes: Current status and future directions. Physiol. Mol. Plant Pathol. 78:51-65.

Hammond-Kosack, K. E., and Jones, J. D. G. 1996. Resistance gene-dependent plant defense responses. Plant Cell 8:1773-1791.

Hoffman, D. D., Diers, B. W., Hartman, G. L., Nickell, C. D., Nelson, R. L., Pedersen, W. L., Cober, E. R., Graef, G. L., Steadman, J. R., Grau, C. R., Nelson, B. D., del Rio, L. E., Helms, T., Anderson, T., Poysa, V., Rajcan, I., and Stienstra, W. C. 2002. Selected soybean plant introductions with partial resistance to Sclerotinia sclerotiorum. Plant Dis. 86:971-980.

Huynh, T. T., Bastien, M., Iquira, E., Turcotte, P., and Belzile, F. 2010. Identification of QTLs associated with partial resistance to white mold in soybean using field-based inoculation. Crop Sci. 50:969-979.

Kim, H. S., and Diers, B. W. 2000a. Inheritance of partial resistance to Sclerotinia stem rot in soybean. Crop Sci. 40:55-61.

Kim, H. S., Hartman, G. L., Manandhar, J. B., Graef, G. L., Steadman, J. R., and Diers, B. W. 2000b. Reaction of soybean cultivars to Sclerotinia stem rot in field, greenhouse, and laboratory evaluations. Crop Sci. 40:665-669.

Kim, H. S., Sneller, C. H., and Diers, B. W. 1999. Evaluation of soybean cultivars for resistance to Sclerotinia stem rot in field environments. Crop Sci. 39:64-68.

Klos, K. L. E., Paz, M. M., Fredrick Marek, L., Cregan, P. B., and Shoemaker, R. C. 2000. Molecular markers useful for detecting resistance to brown stem rot in soybean. Crop Sci. 40:1445-1452.

Kuhlman, E. G., Amerson, H. V., Jordan, A. P., and Pepper, W. D. 1997. Inoculum density and expression of major gene resistance to Fusiform rust disease in loblolly pine. Plant Dis. 81:597-600.

Kull, L. S., Vuong, T. D., Powers, K. S., Eskridge, K. M., Steadman, J. R., and Hartman, G. L. 2003. Evaluation of resistance screening methods for Sclerotinia stem rot of soybean and dry bean. Plant Dis. 87:1471-1476.

Kumar, B., Talukdar, A., Verma, K., Girmilla, V., Bala, I., Lal, S. K., Singh, K., and Sapra, R. L. 2014. Screening of soybean [Glycine max (L.) Merr.] genotypes for yellow mosaic virus (YMV) disease resistance and their molecular characterization using RGA and SSRs markers. Aust. J. Crop Sci. 8:27-34.

Lancashire, P. D., and Jones, D. G. 1985. Components of partial resistance to Septoria nodorum in winter wheat. Ann. Appl. Biol. 106:541-553.

Lumsden, R. D. 1979. Histology and physiology of pathogenesis in plant diseases caused by Sclerotinia species. Phytopathology 69:890-896.

McDonald, M. R., Gossen, B. D., Kora, C., Parker, M., and Boland, G. 2013. Using crop canopy modification to manage plant diseases. Eur. J. Plant Pathol. 135:581-593.

Mideros, S., Nita, M., and Dorrance, A. E. 2007. Characterization of components of partial resistance, Rps2, and root resistance to Phytophthora sojae in soybean. Phytopathology 97:655-662.

Parlevliet, J. E. 1979. Components of resistance that reduce the rate of epidemic development. Annu. Rev. Phytopathol. 17:203-222.

Peltier, A. J., and Grau, C. R. 2008. The influence of light on relationships between Sclerotinia stem rot of soybean in field and controlled environments. Plant Dis. 92:1510-1514
Pennypacker, B. W., and Risius, M. L. 1999. Environmental sensitivity of soybean cultivar response to Sclerotinia sclerotiorum. Phytopathology 89:618-622.

Pethybridge, S. J., Cobb, A. C., and Dillard, H. R. 2015. Production of apothecia and ascospores of Sclerotinia sclerotiorum. Plant Health Instr. https://www.apsnet. org/edcenter/instcomm/TeachingNotes/Pages/ProductionOfApotheciaAndAscospores aspx

Rashid, K. Y. 1991. Evaluation of components of partial resistance to rust in Flax. Can. J. Plant Pathol. 13:212-217.

Rojas, E. V. 2014. Physiological, anatomical and molecular characterization of partial resistance against Sclerotinia sclerotiorum in soybean. Ph.D. thesis, University of Guelph, Ontario, Canada.

Rousseau, G., Thanh, T. H., Dostaler, D., and Rioux, S. 2004. Greenhouse and field assessments of resistance in soybean inoculated with sclerotia, mycelium, and ascospores of Sclerotinia sclerotiorum. Can. J. Plant Pathol. 84:615-623.

Schwartz, H. F., and Steadman, J. R. 1978. Factors affecting sclerotium populations of, and apothecium production by, Sclerotinia sclerotiorum. Phytopathology 68:383-388.

Shi, Z., Liu, S., Noe, J., Arelli, P., Meksem, K., and Li, Z. 2015. SNP identification and marker assay development for high-throughput selection of soybean cyst nematode resistance. BMC Genomics 16:314.

St. Clair, D. A. 2010. Quantitative disease resistance and quantitative resistance loci in breeding. Annu. Rev. Phytopathol. 48:247-268.

Steadman, J. R., and Cook, G. E. 1974. A simple method for collecting ascospores of Whetzelinia sclerotiorum. Plant Dis. Rep. 58:190.

Stewart, H. E. 1990. Effect of plant age and inoculum concentration on expression of major gene resistance to Phytophthora infestans in detached potato leaflets. Mycol. Res. 94:823-826.

Sutton, D. C., and Deverall, B. J. 1984. Phytoalexin accumulation during infection of bean and soybean by ascospores and mycelium of Sclerotinia sclerotiorum. Plant Pathol. 33:377-383.

Tredway, L. P., Stevenson, K. L., and Burpee, L. L. 2003. Components of resistance to Magnaporthe grisea in "Coyote" and "Coronado" tall fescue. Plant Dis. 87:906-912.

Tu, J. C. 1985. Tolerance of white bean (Phaseolus vulgaris) to white mold (Sclerotinia sclerotiorum) associated with tolerance to oxalic acid. Physiol. Plant Pathol. 26:111-117.

Vasudevan, K., Vera Cruz, C. M., Gruissem, W., and Bhullar, N. K. 2014. Large scale germplasm screening for identification of novel rice blast resistance sources. Front. Plant Sci. 5:505.

Vuong, T. D., Diers, B. W., and Hartman, G. L. 2008. Identification of QTL for resistance to Sclerotinia stem rot in soybean plant introduction 194639. Crop Sci. 48:2209-2214

Vuong, T. D., Hoffman, D. D., Diers, B. W., Miller, J. F., Steadman, J. R., and Hartman, G. L. 2004. Evaluation of soybean, dry bean, and sunflower fore resistance to Sclerotinia sclerotiorum. Crop Sci. 44:777-783.

Waliyar, F., Shew, B. B., Stalker, H. T., Isleib, T. G., Sidahmed, R., and Beute, M. K. 1994. Effect of temperature on stability of components of resistance to Cercospra arachidcola in peanut. Phytopathology 84:1037-1043.

Wegulo, S. N., Yang, X. B., and Martinson, C. A. 1998. Soybean cultivar responses to Sclerotinia sclerotiorum in field and controlled environment studies. Plant Dis. 82:1264-1270.

Willbur, J. F., Ding, S., Marks, M. E., Lucas, H., Grau, C. R., Groves, C. L., Kabbage, M., and Smith, D. L. 2017. Comprehensive Sclerotinia stem rot screening of soybean germplasm requires multiple isolates of Sclerotinia sclerotiorum. Plant Dis. 101:344-353.

Xue, A. G., and Davidson, C. G. 1998. Components of partial resistance to black spot disease (Diplocarpon rosae Wolf) in garden roses. HortScience 33:96-99.

Yanar, Y., and Miller, S. A. 2003. Resistance of pepper cultivars and accessions of Capsicum spp. to Sclerotinia sclerotiorum. Plant Dis. 87:303-307.

Young, N. D. 1996. QTL mapping and quantitative disease resistance in plants. Annu. Rev. Phytopathol. 34:479-501. 